\title{
ORTHOPAEDIC ASPECTS OF RETT'S SYNDROME: BRIEF REPORT
}

\author{
A. P. ROBERTS, A. N. CONNER
}

Rett's syndrome is a genetically determined disorder of the extrapyramidal system which affects an estimated one in 15,000 girls. It is characterised by normal early development, with regression during the second year of life, leading to involuntary movements, and severe mental and physical handicap. The disease has been divided into three types (Table I); these do not necessarily reflect chronological progression though they may do so, and most children are chairbound by the age of eleven years. We have studied the orthopaedic abnormalities in 22 girls, aged 3 years 9 months to 27 years (mean 12 years). One girl had Type I disease, ten had Type II and eleven had Type III. Four girls, with ages ranging from four years to 15 years had never walked. There were three common deformities: scoliosis; dislocation of a hip; and lower limb contractures. Scoliosis. Sixteen children had a scoliosis measuring over $5^{\circ}$. In the eleven for whom there were serial measurements the mean rate of progression was $11^{\circ}$ per year (Fig. 1). The frequency and severity of the scoliosis increased as the disease progressed: no children with Type I disease had scoliosis, but half of those with Type II and all those with Type III disease were affected. With Type II the mean curvature was $28^{\circ}$ and with Type III $55^{\circ}$. The most severe deformities were in the thoracolumbar area.

Dislocation of the hip. Two girls with Type III disease had a dislocated hip contralateral to a thoracolumbar scoliosis. In one there was radiographic evidence that the hip had dislocated before the spine had become deformed. Four other children, all chairbound and with scoliosis, had an adduction deformity of the contralateral hip. One had had an adductor tenotomy with no benefit. Contractures. Three girls, all chairbound, had bilateral flexion deformities of the knees. None had had treatment. Six girls, three of whom were still ambulant, had an equinus or equino-varus deformity of one foot. Two were untreated, one had been splinted with little benefit, and three had had soft tissue correction with good results. Discussion. The deformities found in children with Rett's syndrome are similar to those in other severe paralytic conditions of childhood, such as cerebral palsy and the muscle dystrophies, and treatment should presumably follow the principles established in those diseases. Once scoliosis has developed a total contact orthosis may be

A. P. Roberts, FRCS, Orthopaedic Registrar

A. N. Conner, FRCS, Consultant Orthopaedic Surgeon

Royal Hospital for Sick Children, Yorkhill, Glasgow G3 $8 \mathrm{SH}$ Scotland.

Correspondence to Mr A. P. Roberts.

(C) 1988 British Editorial Society of Bone and Joint Surgery 0301-620X/88/4R64 \$2.00

$J$ Bone Joint Surg [Br] 1988;70-B:674.

Table I. Classification of Rett's syndrome after Kerr and Stephenson 1985

\begin{tabular}{|c|c|c|c|}
\hline Features & Type I & Type II & Type III \\
\hline Gait & $\begin{array}{l}\text { Broad based } \\
\text { Poor balance }\end{array}$ & $\begin{array}{l}\text { Poor balance } \\
\text { and mobility }\end{array}$ & Non-ambulant \\
\hline Muscle tone & Hypotonic & Variable & Spastic \\
\hline Movements & $\begin{array}{l}\text { Rhythmic hand } \\
\text { movements, jerky } \\
\text { trunk movements } \\
\text { and dystonia }\end{array}$ & $\begin{array}{l}\text { Rhythmic hand } \\
\text { movements and } \\
\text { dystonia }\end{array}$ & Fewer movements \\
\hline
\end{tabular}

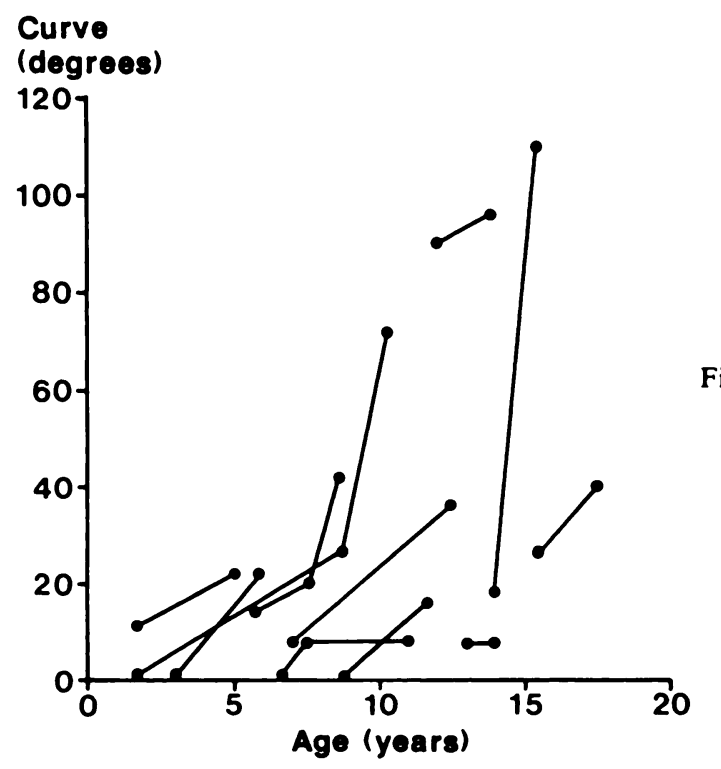

prescribed, provided the curve is small and the child still ambulant; but in late cases when the child is chairbound, a seat insert is often best. However, there must be a balance between supporting the spine and allowing the child freedom; too rigid an adherence to splints may lead to behavioural problems. In a few cases it may be best to operate despite the risks of anaesthesia and the problems of instrumentation with soft bone.

Hip deformities should be discouraged by appropriate physiotherapy, but in late cases tenotomy is advised or, if this fails, femoral osteotomy. Dislocated hips do not need to be reduced, but severe deformity can be corrected by subtrochanteric osteotomy. While these children are ambulant, lower limb contractures are best corrected by soft tissue release, but once they are chairbound no treatment is needed except perhaps for cosmetic reasons.

We wish to thank Dr A. M. Kerr and Dr J. B. P. Stephenson for permission to study their patients.

\section{REFERENCE}

Kerr AM, Stephenson JBP. Rett's syndrome in the West of Scotland $\mathrm{Br}$ Med J 1985;291:579-82. 